\title{
Pregnancy-related school dropout and prior school performance in South Africa
}

Monica J. Grant

Kelly Hallman

Population Council

Follow this and additional works at: https://knowledgecommons.popcouncil.org/departments_sbsr-pgy

Part of the Demography, Population, and Ecology Commons, Family, Life Course, and Society Commons, Gender Equity in Education Commons, and the International Public Health Commons How does access to this work benefit you? Let us know!

\section{Recommended Citation}

Grant, Monica J. and Kelly Hallman. 2006. "Pregnancy-related school dropout and prior school performance in South Africa," Policy Research Division Working Paper no. 212. New York: Population Council. 


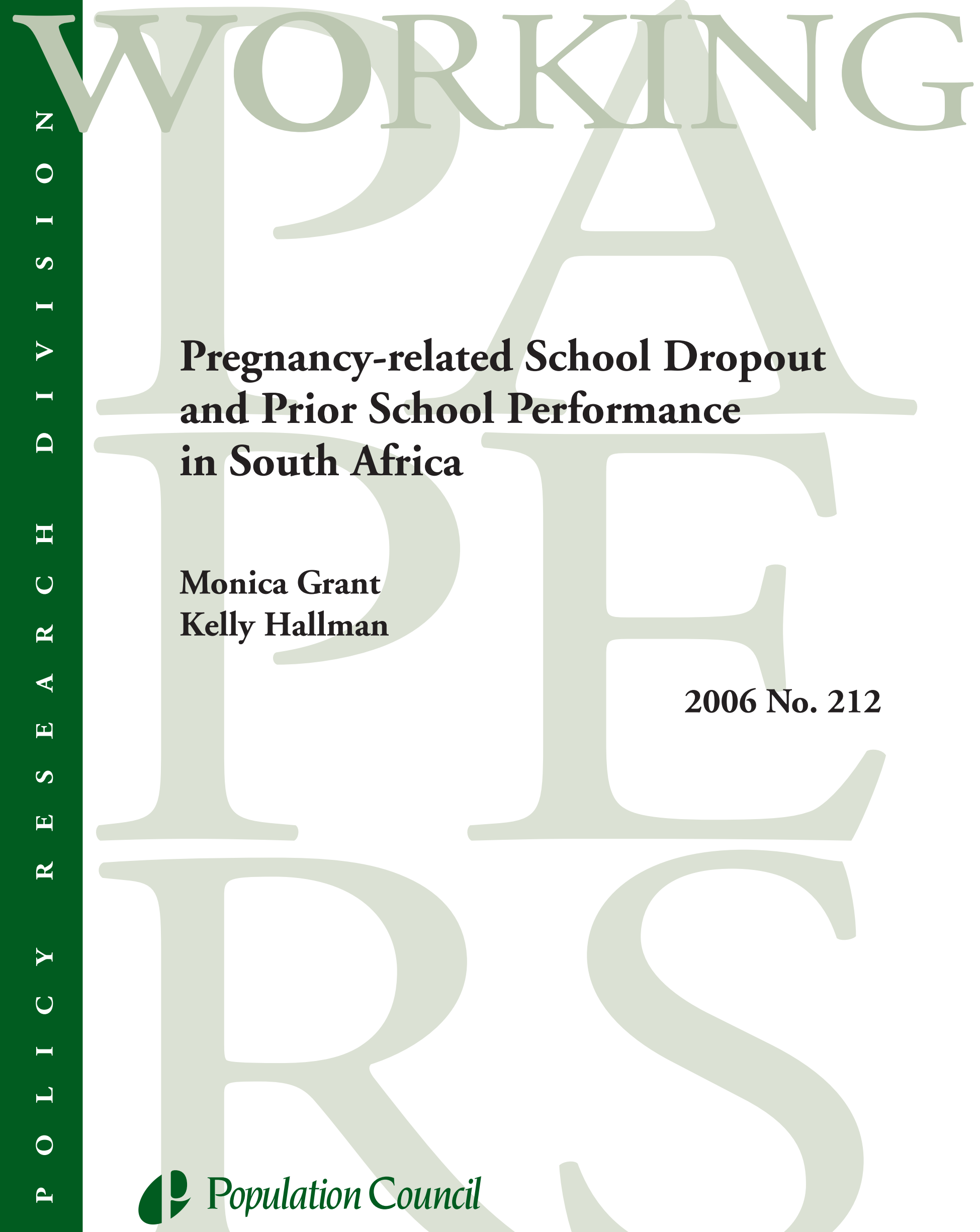




\section{(P) Population Council}

One Dag Hammarskjold Plaza

New York, New York 10017 USA

www.popcouncil.org

pubinfo@popcouncil.org

This material may not be reproduced without written permission from the authors. For a list of Policy Research Division Working Papers, including those that are currently available for downloading in PDF format, see www.popcouncil.org/publications/wp/prd/rdwplist.html.

ISSN: $1554-8538$

(C) 2006 The Population Council, Inc. 
Pregnancy-related School Dropout and Prior School Performance in South Africa

\author{
Monica Grant \\ Kelly Hallman
}

Monica Grant is a doctoral student, Graduate Group in Demography, University of Pennsylvania, Philadelphia. Kelly Hallman is Research Associate, Population Council, New York.

We would like to thank Cynthia B. Lloyd and Barbara S. Mensch for helpful comments on an earlier draft of this paper. We would like to acknowledge the generous support of the Department for International Development (UK), the William and Flora Hewlett Foundation, and the Andrew W. Mellon Foundation. 


\begin{abstract}
Although considerable attention has been paid to the prevalence of adolescent childbearing in the less developed world, few studies have focused on the educational consequences of schoolgirl pregnancy. Using data collected in 2001 in KwaZulu-Natal, South Africa, this paper examines the factors associated with schoolgirl pregnancy, as well as the likelihood of school dropout and subsequent re-enrollment among pregnant schoolgirls. This analysis triangulates data collected from birth histories, education histories, and data concerning pregnancy to strengthen the identification of young women who became pregnant while enrolled in school and to define discrete periods of school interruption prior to first pregnancy. We find that prior school performance - defined as instances of grade repetition or non-pregnancy-related temporary withdrawals from school - is strongly associated with a young woman's likelihood of becoming pregnant while enrolled in school, dropping out of school if she becomes pregnant, and not returning to school following a pregnancy-related dropout. Young women who are the primary caregivers to their children are also significantly more likely to have left school than are women who shared or relinquished childcare responsibilities. Furthermore, young women who lived with an adult female were significantly more likely to return to school following a pregnancyrelated dropout. Given the increasing levels of female school participation in sub-Saharan Africa, our findings suggest that future studies will benefit from exploring the causal relationships between prior school experiences, adolescent reproductive behavior, and subsequent school attendance.
\end{abstract}


Despite recently slowed rates, the proportion of girls enrolling in school has increased in sub-Saharan Africa over the past two decades (Hewett and Lloyd 2005; NRC-IOM 2005). Improvements in the proportion of girls who enter school and who complete primary school have decreased the gap between male and female educational attainment in the region. School attendance in sub-Saharan Africa is marked by prevalent grade repetition and temporary school withdrawals, however, leading many young people to remain enrolled in primary school well into their late teens. South Africa has one of the highest levels of school enrollment in Africa, with a majority of 15-19-year-old males and females enrolled in school-approximately 85 and 79 percent, respectively in 1998 (NRC-IOM 2005).

Simultaneous to the improved school participation of young women have been declines in adolescent childbearing. Throughout sub-Saharan Africa, a smaller proportion of 20-24-yearold women than of 40-44-year-olds gave birth prior to age 18 (NRC-IOM 2005). South Africa has remained an exception to this pattern, however; over the past two decades, the proportion of young women who gave birth prior to age 18 has remained the same, if not increased slightly, and recent data suggest that more than 30 percent of 18-year-olds have given birth (Mahy and Gupta 2002; NRC-IOM 2005).

Therefore, despite the declining proportion of women across sub-Saharan Africa who become adolescent mothers, as more young women remain in school past puberty more students are exposed to the risk of becoming pregnant. Although the literature addressing adolescent fertility and childbearing in the developing world is large, few studies focus on the prevalence of schoolgirl pregnancy and its relationship to prior school experiences and subsequent educational attainment (Mensch et al. 2001; Eloundou-Enyégué 2004). In particular, one study by EloundouEnyégué (2004) found that although pregnancy was not the source of all dropouts among girls in Cameroon, it was the greatest contributor to the gender gap in educational attainment, particularly at the secondary level.

In a previous study conducted in South Africa, the authors noted that although girls advance more quickly than boys through primary school, girls begin to falter at the secondary level. Most school delays in the sample were attributed to economic constraints; however, among 20-22-year-old females who experienced a school delay, more than one-fourth attributed their delay to a pregnancy (Hallman and Grant 2003 and 2004). Although in many settings having a child marks the end of schooling for girls, a policy formalized in South Africa in 1996 but informally upheld previously by some school principals allows pregnant girls to stay in school and also allows young mothers to do so if they can manage logistically and financially (Kaufman et al. 2001). This policy, although not universally enforced, is credited with the observed lack of gender differences in total educational attainment and is believed to contribute to the observed long delay before the birth of a second child to adolescent mothers in South Africa. Using the 1993 SALDRU data, Maharaj and her colleagues (2000) found that approximately 35 percent of African girls aged 19 and younger who had given birth at least once were currently attending school. A study using 2001 data from KwaZulu-Natal found that 32 percent of 14-19-year-olds who had ever been pregnant were currently attending school (Hallman and Grant 2003).

In light of the high levels of school participation and secondary-school completion in South Africa, the disruptive role of schoolgirl pregnancy assumes particular salience. In examining the issue, we explore in particular the widely held but problematic assumption that 
most young women who drop out of school following a pregnancy would otherwise have remained in school. By combining information about birth and education histories collected in a survey of adolescents in KwaZulu-Natal, South Africa, this analysis examines the competing risks that a young woman will become pregnant while she is enrolled in school, that she will drop out of school for non-pregnancy-related reasons, and that she will remain in school and not become pregnant. We explore the educational trajectories subsequent to a schoolgirl pregnancy, with a particular focus on the association between schooling outcomes and prior academic performance. Combined with variables controlling for individual and household characteristics, these associations present an opportunity to question the causal order of academic and childbearing status among young women.

\section{Schoolgirl Pregnancy}

Although considerable attention has been paid to the prevalence of adolescent childbearing in the less developed world (see NRC 1993; Mensch et al. 1998; Singh 1998; Singh et al. 2000; NRC-IOM 2005), few data are available concerning the likelihood that a young woman will become pregnant while she is still enrolled in school. Where data are available they usually pertain to births rather than to pregnancy. In sub-Saharan Africa, the combined effects of increasing levels of school enrollment, delayed school entry, grade repetition, and periods of temporary withdrawal from school lead many young women to remain enrolled at the primary or junior secondary level well past puberty and into their late teens, thus increasing their risk of pregnancy-related school disruptions (Lloyd et al. 2000; Hewett and Lloyd 2005). Few studies examine the direct association between continued school enrollment and adolescent pregnancy. Various qualitative studies, many from Southern Africa, have attempted to examine aspects of this issue, most using focus-group discussions and semistructured interviews to identify policy factors perceived to contribute to the risk of schoolgirl pregnancy (HSRC 2005), what adolescents perceive to be the consequences of schoolgirl pregnancy (Bledsoe 1992; HSRC 2005), the resources and strategies that pregnant adolescents draw upon (Preston-Whyte 1990; Tanga and Uys 1996; Kaufman et al. 2001), and the factors that influence whether or not a young woman returns to school following a pregnancy (Kaufman et al. 2001; Johnson-Hanks 2002; HSRC 2005). Although these studies have made a significant contribution to the way that schoolgirl pregnancy is conceptualized and have identified issues for policy intervention, few quantitative studies exist to facilitate generalization of these results.

School enrollment is most often viewed as protective, providing a structured setting in which children receive support and develop their capabilities and knowledge. The associations between increased educational attainment and subsequent age at marriage, total fertility, child health, and children's schooling are well documented. More scattered evidence from less developed countries suggests that young women who are enrolled in school are less likely to be sexually active, less likely to begin childbearing, and more likely to use a contraceptive, compared with women who are not enrolled in school (NRC-IOM 2005). In one of the few indepth country studies on the subject, Shapiro and Tambashe (1996) used a discrete-time hazard analysis to explore the timing of first birth in Kinshasa, Zaire. Treating school enrollment as a time-varying covariate, they found that women who were enrolled in school were significantly 
less likely to begin childbearing than were women who were no longer enrolled, controlling for age, parental education, and other household characteristics.

A study conducted in Kenya found that girls with poor school performance were significantly more likely than the best students to become pregnant. The authors speculated that the high incidence of grade repetition among low achievers may be partially responsible, lengthening the period in which girls remain in school and are at risk of becoming pregnant (Division of Family Health/GTZ Support Unit 1988). A perceived lack of returns to continued schooling - fueled by low expectations of advancing - may influence girls' simultaneous decision to begin childbearing and to drop out, however, thereby obscuring any causal relationship between the two phenomena.

Evidence suggests that schools do not impart protection equally. Mensch and her colleagues (2001) found in Kenya that a gender-neutral atmosphere in school appeared to reduce the risk that girls will engage in premarital sex; in schools with gender-biased atmospheres, girls were more likely to drop out. In the latter population, pregnancy followed dropout and was not the cause of it.

Both of these studies address the problematic assumption that everyone who becomes pregnant and drops out of school prematurely otherwise would have continued her education. The risk of early childbearing and school dropout may be influenced by common underlying factors, further muddling the association between these two events. Kirby (2001), for example, asserts that sexual risk-taking has many nonsexual antecedents, including poor school performance, whereas Hallman and Grant (2003) provide evidence that both early school leaving and adolescent pregnancy are strongly associated with low economic status. As Lloyd and Mensch (1995: 85) summarized,

Rather than pregnancy causing girls to drop out, the lack of social and economic opportunities for girls and women and the domestic demands placed on them, coupled with the gender inequities of the education system, may result in unsatisfactory school experiences, poor academic performance, and acquiescence in or endorsement of early motherhood.

Furthermore, little discussion has addressed the reasons young women give for leaving school prematurely. Except in qualitative studies, the simultaneous decisions related to pregnancy and leaving school are rarely examined. In particular, if a young woman gives a reason other than pregnancy for discontinuing her education, whether she is also pregnant at the time she leaves school is rarely taken into account. Particularly for young women who mention such dominant concerns as financial issues, family obligations, or a lack of interest in school, a pregnancy may serve as an unacknowledged catalyzing force for the timing of school dropout. As Eloundou-Enyégué (2004: 517) notes, "Respondents may downplay pregnancy as a factor in some of the dropouts that are imputed to marriage or to the lack of money." Likewise, young women who mention pregnancy as their reason for school leaving may be equally influenced by their family's financial situation or by potential caregiving arrangements that will be available after the child is born. These factors may be significant in determining how a schoolgirl reacts to pregnancy and whether she will resume her education after her child is born. 


\section{Pregnancy-related school dropouts}

Even when studies focus on pregnancy-related school dropout, they do not address directly the question of which schoolgirls who become pregnant are likely to drop out of school. In most settings, if a girl becomes visibly pregnant, she is required to withdraw. If a young woman terminates her pregnancy before it is visible, however, school dropout can be avoided. Despite high rates of teenage pregnancy and the availability since 1996 of legal termination-ofpregnancy services in South Africa, many adolescents are not aware of such services (SADOH 1999) and availability of these services in public facilities is still lacking (Dickson et al. 2003). Statistics on use of abortion services among adolescents are not readily available. One hospitalbased study in Soweto found the prevalence of legal abortion among pregnant teenagers to be 16 percent in 2001 (Buchmann et al. 2002).

Meekers and Ahmed (1999) examine the probability of prior school dropout among pregnant women, but, because of data limitations, provide no control for whether the woman was enrolled in school at the time of her pregnancy. In contrast, Eloundou-Enyégué (2004) examines the relative role of pregnancy- and non-pregnancy-related school dropout in shaping the gender gap in educational attainment, but does not address what happens to girls who become pregnant while enrolled in school but do not drop out at that time.

The broader literature on school dropout provides many insights that are relevant for determining dropout among pregnant schoolgirls, however; selected studies are discussed below. In South Africa, even though little gender difference is found in educational attainment (Case and Deaton 1999; Lam 1999; UNDFW 2000), some researchers have given attention to the factors associated with female dropout (Fuller and Liang 1999; Hunter and May 2002). These studies focus on the association between a household's economic resources, its social structure, its labor demands, and the continued schooling of young women.

Using a non-cause-specific hazard model for the factors associated with school dropout, Fuller and Liang (1999) found an association between a family's financial strength, measured by level of household expenditure and access to credit, and the likelihood that a daughter will remain in school. In an earlier study conducted in Botswana, they found that household-asset ownership and housing quality were also consistently related to girls' educational attainment; these reflected the accumulated wealth and investment attitude of the household better than did short-term measures of consumption (Fuller et al. 1995, cited in Fuller and Liang 1999). Edmonds (2004) finds that receipt among elderly household residents of the state old-age pension in South Africa significantly increases school attendance of coresident children. Although education is a household investment that is often protected from external shocks (Moser 1996; Hunter and May 2002), the ability of a household to sustain this long-term investment may be hampered by short- and intermediate-term economic difficulties and labor demands. An adolescent's unwanted pregnancy not only endangers the long-term investment made in a daughter's education (NRC 1993), but also creates additional financial issues that poor households may be unable to handle. Qualitative results from the recent HSRC (2005) rural schooling study in South Africa indicate that among the small proportion of schoolgirls who apply for and receive the state child-support grant after giving birth, even though the money is seen as an important source of poverty relief for the extended family, it causes tension within the 
household. Some girls reported that the benefit of receiving the grant was more than offset by the additional hardships that having a baby imposes upon their lives.

Household labor demands also influence the likelihood that a young woman will remain in school whether or not she is pregnant. Fuller and Liang (1999) found that a mother's participation in the formal wage sector may depress a daughter's likelihood of remaining in school, perhaps as a result of increased household labor demands. Hallman and her colleagues (2005) found that urban mothers of preschoolers in Guatemala are more likely to work for pay and work more hours when daughters aged 15-18 are coresident. Another analysis from urban Brazil indicates that girls aged 10 and older are a major source of childcare for preschoolers in their household (Connelly et al. 1996). The availability of other adult women in the household to share domestic responsibilities may be even more critical following childbirth to an adolescent when caregiving demands for the baby would otherwise make the girl's return to school prohibitively difficult. An ethnographic study in Cameroon indicated that young women sent their children to live in the father's household or otherwise relinquished parental rights to other relatives in order to continue their education (Johnson-Hanks 2002). Qualitative research in South Africa found that some young women marry or move into their partner's home following a pregnancy, and are thereby subject to the financial and labor priorities of their new household, which may not place a priority on their continuing education (Kaufman et al. 2001). Maharaj and her colleagues (2000) demonstrate that adolescent mothers whose children are not coresident are more likely to be attending school currently.

Although coresidence with parents may be an important indicator of the social support systems available to a young woman, Meekers and Ahmed (1999) found that women who lived with their parents at the time of their first pregnancy were two times more likely than women who lived elsewhere to have dropped out of primary school as a result of pregnancy. This finding may not be entirely clear, however, because the study sample consisted of all women aged 19-34 who had ever attended school and were unmarried at the time of their first birth, without reference to the mother's age at first birth or whether she was enrolled in school at the time of her first pregnancy. Without these controls, the likelihood of pregnancy-related primary-school dropout is a closer proxy to the timing of first birth, because older women who are no longer living with their parents or enrolled in school when they become pregnant are clearly less likely to have a pregnancy-related school dropout.

\section{Returning to school following a pregnancy-related dropout}

Although more and more countries now allow girls to stay in and/or return to school after a pregnancy, these policy changes have had little effect so far on behavior (NRC/IOM 2005). South Africa is among the few countries in sub-Saharan Africa that allow a young woman to return to school after a pregnancy. Although a large proportion of young women continue their education following the birth of their first child, many do not. Many of the same household and family characteristics that influence a young woman's likelihood of dropping out of school in response to her pregnancy also influence her likelihood to resume schooling. Meekers and Ahmed (1999) found that among young women in Botswana who dropped out of school

following a pregnancy and subsequently returned to school, the majority of returnees stayed in 
school until they received their matriculation certificate. They speculate that highly motivated students with good school performance prior to pregnancy are those most likely to return, but also that any student who manages to return to school following a pregnancy is likely to have the impetus to advance her education.

A further factor influencing school continuation may be a young woman's fertility subsequent to the birth of her first child. Although South Africa's total fertility rate is low (2.9 children per woman of reproductive age in 1998) compared with that of other countries in subSaharan Africa and the median birth interval for second and third births is nearly 50 months long (SADOH 1999), young women who have a second child shortly after the first is born may, for practical reasons, no longer have the option of returning to school. Disentangling a woman's education and fertility objectives is difficult, however; the possibility of returning to school may lead most women to postpone their second birth if they can (Kaufman et al. 2001).

In this study, we examine the relationship of pregnancy and schooling outcomes to socioeconomic and household factors such as coresidence with mothers and fathers, household size and composition, education of adult household members, household-asset ownership, and urban/rural residence. We also explore the influence of the respondent's previous academic performance, such as school delays, repeated grades, and age of school entry. By examining the relationships among school delays, educational attainment, and early childbearing, this study contributes to our understanding of the variety of life choices made by young women during their transition to adulthood and sheds light on how potential policies and programs may be better designed and targeted to improve the educational outcomes and sexual and reproductive health of young women.

\section{DATA AND METHODS}

The data used here are drawn from the 2001 survey "Transitions to Adulthood in the Context of AIDS in South Africa," conducted in KwaZulu-Natal Province, South Africa (Rutenberg et al. 2001; Magnani et al. 2003). KwaZulu-Natal is characterized by conservative cultural values with regard to gender roles, high HIV prevalence, and high rates of poverty and inequality. KwaZulu-Natal Province has the largest population in South Africa, about one-half of whom reside in urban areas (as classified by the South African Census Bureau); it is the home of the Zulu nation, and Zulu speakers comprise the majority of the population ( 82 percent), with Indians making up another 9 percent, and whites and coloreds together comprising 9 percent.

Durban Metro and Mtunzini Magisterial District were purposively chosen for the study site, because they represented urban, transitional, and rural areas of KwaZulu-Natal. A modified stratified, multistage cluster sampling method (Turner et al. 1996) was used; census enumeration areas from the 1996 census served as the primary sampling units. Interviews were conducted with all willing young people aged 14-24 within each census enumeration area. Data were collected directly from each young person, rather than from a parent or other adult in the household, as in the Elondou-Enyégué (2004) study.

In addition to standard questions regarding schooling and educational attainment, the Transitions survey collected a complete educational history for all respondents, beginning with the year the respondent first enrolled in school and ending with her most recent year of 
enrollment. For each year, the respondent reported whether she enrolled during that particular school year, withdrew during the school year, or repeated the grade because of poor performance. Every time the respondent reported a withdrawal from school for all or part of an academic year, she was asked why her education was interrupted. Because the majority of young people in South Africa have experienced some form of delay or interruption of schooling, this level of detail provides an unusual opportunity to track a respondent's educational progress.

In a module separate from education history, a detailed birth history was collected for every live birth. Information on the month and year of each birth was matched to the respondent's education history, enabling us to triangulate reported reasons for interruptions in education against the reported timing of pregnancy and childbirth. A girl not enrolled in school when she gave birth was defined as having been a "pregnant schoolgirl" if she gave birth within nine months of the end of the last school year she attended. Of these young women, 33 percent of 14-19-year-olds and 25 percent of 20-24-year-olds either withdrew partway through the school year in which they became pregnant or failed that grade. Although it is difficult to determine whether these interruptions were the result of the pregnancy or whether the pregnancy resulted from the interruptions (for example, in cases of those who became pregnant during a period of truancy within any particular school year), for the purposes of this analysis, these young women are defined as having been enrolled in school at the time they became pregnant.

The survey also included a comprehensive set of questions regarding any pregnancies that the respondent had experienced. In particular, data were collected on whether the respondent was enrolled in school at the time of her first pregnancy, whether she dropped out of school because of her pregnancy, and whether she was able subsequently to return to school. Combined with the education and birth histories, these questions improve the reliability of reporting related to educational attainment and schooling interruptions related to pregnancy and childcare.

Because we were able to identify pregnant schoolgirls with greater specificity than most surveys allow, examining respondents' stated reasons for disruption of their schooling for those who left school while they were pregnant is especially useful. Table 1 shows the distribution of reasons given by all respondents who left school at the time they were pregnant, regardless of whether they later resumed their education. Seventy-six percent of respondents reported pregnancy as their reason for dropping out of school, although an additional 6 percent reported that they left school in order to care for a child. In contrast, 11 percent of women reported that they dropped out of school because they were unable to pay the school fees. Because we know that these respondents were also pregnant at the time they left school, it is unclear to what extent the pregnancy may have been a precipitating event or an additional financial burden that made school continuation difficult. Indeed, of pregnant schoolgirls who had not yet returned to school by the time of the survey, 19 percent cited their inability to pay school fees as the reason. In these cases, disentangling the relative importance of pregnancy and economic vulnerability in determining school dropout is difficult. This determination is complicated because respondents were allowed to give only one reason for dropping out of school or not completing the academic year. Thus, the stated reason may have been the most important factor influencing the decision to leave school, but its relative importance cannot be verified from the available data.

The pregnancy questions also shed light on the prevalence of pregnancies that did not result in live births. Less than 3 percent of women who had ever been pregnant did not report 
ever having given birth, excluding women who were pregnant at the time of the survey; the majority of the pregnancies in these cases (14 of 17) were reported to have ended in a medical or otherwise induced abortion. In light of this low number of incomplete pregnancies, many pregnancies that ended in abortion or miscarriage likely were unreported. Although these missing data might bias the measurement of factors associated with schoolgirl pregnancy, they should have little impact on the analysis of pregnancy-related dropout. In their evaluation of schoolgirls' sexual activity and pregnancy in Kenya, Mensch and her colleagues (2001) assumed that unreported pregnancies were not visible or publicly known and most likely ended in miscarriage or abortion. Because these unreported pregnancies did not interfere with schooling, the authors did not consider them to be of concern for their analysis. In the few studies that mention abortion in the context of schoolgirl pregnancy, it is seen as an option used by young women to avoid school authorities' detection of the pregnancy and subsequent expulsion (NRC 1993; Kaufman et al. 2001).

From the schooling data we can construct variables pertaining to academic performance prior to pregnancy, such as age at school entry, the number of grades repeated prior to becoming pregnant, and the grade in which a girl was enrolled at the time of pregnancy (see Table 1 for the mean values of the independent variables). Information was also collected about parental coresidence and survival, the educational attainment of adult household members, household size, household-asset ownership, residence (urban or rural), and race. The distribution of these variables is presented in Table 2. Unfortunately, these indicators reflect conditions only at the time of the survey, not at the time of the pregnancy. Adolescent childbearing could, plausibly, have a negative effect on household economic conditions, although this issue is not explored here. Furthermore, current household composition and parental coresidence may not represent the level of familial support available at the time of the pregnancy. Current household composition may have developed in response to the need for childcare assistance; therefore, these variables remain relevant to the discussion.

Overall, the majority of female respondents aged 14-19 (78 percent) were enrolled in school at the time of the survey, compared with only 28 percent of 20-24-year-old females. Among 20-24-year-old females still enrolled in school, none was enrolled at the primary level, but more than 50 percent were still enrolled in secondary school, indicating prior school delays. Thirteen percent of all 14-19-year-old respondents became pregnant while enrolled in school, compared with 38 percent of 20-24-year-old respondents. Clearly, with such a large proportion of the younger cohort still enrolled in school, many may still become pregnant before they complete secondary school.

In our analysis, we use a multinomial logit regression on discrete time data to explore the competing risks that a young woman will become pregnant while enrolled in school, that she will drop out of school for reasons other than pregnancy, and that she will remain enrolled in school. These discrete time data are organized by school grades; this structure allows the explanatory variables for school performance to vary over time and also censors those young women who are still enrolled in school and have not yet become pregnant or graduated. We restrict our attention to young women who became pregnant while enrolled in school and use logistic regression to measure the relative likelihood that a respondent dropped out of school in response to her pregnancy. Finally, among those young women who leave school at the time of their pregnancy, 
we explore the likelihood of their returning to school, using a discrete-time hazard model based on the number of years since they dropped out of school.

\section{RESULTS}

Although pregnancy and motherhood do not always interrupt a young woman's education in South Africa, they introduce a new set of circumstances that influence future decisions related to schooling. Therefore, for the purposes of this analysis, we consider pregnancy as a schoolrelated outcome. Figure 1 uses current-status data to depict the distribution of young women by schooling status. In addition to the three categories previously defined-young women who become pregnant while enrolled in school, who drop out of school for reasons other than pregnancy, and who remain enrolled in school and have not yet become pregnant - this figure also identifies the proportion who successfully completed grade 12 and did not become pregnant while enrolled in school. Under this design, the four categories depicted in Figure 1 are mutually exclusive.

Few of the youngest women in the sample had discontinued their schooling; more than 90 percent of 14- and 15-year-olds were still enrolled in school at the time of the survey. Even among 16-year-olds, less than 5 percent had become pregnant while enrolled in school, and only 7 percent had dropped out of school for non-pregnancy-related reasons. Despite continued enrollment in school, however, many of these young women had already experienced other types of delays in schooling, such as delayed entry to grade one, grade repetition, or a period of temporary school withdrawal at a younger age.

Respondents who began school on schedule at about age six and progressed through school without interruptions should have completed grade 12 at about age 18 . Only 21 percent of 18-year-olds had completed grade 12 by the time of the survey, however. An additional 46 percent were still enrolled in school and had not yet become pregnant. In contrast, 24 percent of 18-year-olds had become pregnant while enrolled in school, regardless of whether they went on to drop out of school, and 9 percent had dropped out for non-pregnancy-related reasons. By age 20 , only 34 percent of women had completed grade 12, whereas only 12 percent of those with less than grade 12 attainment remained in school. Schoolgirl pregnancy continued to be a more common cause of interrupted education than reasons not related to pregnancy; by age 20, 35 percent of women had become pregnant while enrolled in school, and 19 percent had dropped out of school for non-pregnancy-related reasons.

We use multinomial logit regressions to analyze the competing risk of pregnancy and non-pregnancy-related school dropout relative to remaining in school, as shown in Table 3. Each respondent contributed one observation for each grade of school she attended. As these young women drop out of school for a non-pregnancy-related reason or become pregnant, the school year in which this event occurs is coded to reflect this event. At all grades prior to these eventsand at all grades among young women who are still enrolled in school and have never been pregnant - the respondent is coded as being still in school. For those young women who became pregnant, the likelihood of remaining in school or dropping out of school at the time of pregnancy is explored in the next stage of the analysis below. To simplify the analysis, young 
women who successfully completed grade 12, as depicted in Figure 1, are classified for the multinomial logit as "still enrolled in school" at grade 12 rather than in a fourth category.

Although schoolgirl pregnancy and non-pregnancy-related school dropout are associated with many of the same characteristics, some important differences emerge. The risk of either becoming pregnant or of school dropout due to non-pregnancy-related reasons increases with each additional grade, as expected. The one exception is grade 12, the last year of secondary school, where the risk of dropping out of school is not significantly different from the risk experienced at grade 8, the first year of secondary school in South Africa. As students approach their matriculation certificate, their likelihood of dropping out of school decreases. The relative risk of becoming pregnant is greatest in grade 12 , however.

In Model 1, race is not significantly associated with school dropout; only Asians have a significantly lower relative risk of becoming pregnant than blacks. The relative risk of both outcomes declines as household socioeconomic status increases. Respondents whose mothers lived in their household at the time of the survey are significantly less likely to have dropped out of school relative to respondents whose mothers lived elsewhere or were deceased. Coresidence with mothers is not significantly associated with the risk of becoming pregnant. In contrast, paternal coresidence is significantly associated with a lower risk of becoming pregnant, but is not associated with the risk of dropping out of school.

Increasing household size is significantly associated with an increased risk of becoming pregnant, but not with dropping out of school. This finding could be an artifact of the data, given that the respondent's child is included in the count of current household members. The risk of either becoming pregnant or dropping out of school also declines significantly as the educational attainment of the household head increases. Finally, residence in urban areas is not significantly associated with the risk of becoming pregnant or dropping out of school, relative to living in a rural area.

Model 2 added variables controlling for prior school experiences. Each year that school entry was delayed is associated with a 48 percent greater risk of dropping out of school and with a 65 percent greater risk of becoming pregnant. Women who had previously withdrawn temporarily from school are more than two times more likely to drop out of school permanently than are women who did not. Surprisingly, the experience of temporary withdrawal from school is not significantly associated with the risk of becoming pregnant. It is not possible, however, to identify periods of school withdrawal that occur within the same school year as a pregnancy if that pregnancy leads to school dropout; only recent instances of truancy may be associated with the risk of pregnancy, rather than a history of irregular attendance. Women who had repeated a grade are 64 percent more likely to have dropped out of school and seven times more likely to become pregnant, relative to those who had not.

The inclusion of the school-history variables in Model 2 also influences the significance of the other explanatory variables. Whereas being Asian is associated in Model 1 with a decreased risk of becoming pregnant, in Model 2 Asian respondents are significantly more likely than black respondents to drop out of school. Furthermore, a significant difference is no longer found in the likelihood of becoming pregnant among women living in households of low-middle and middle socioeconomic status, relative to women in the lowest quintile. Living in a household 
where the head had received some postsecondary schooling is no longer significantly associated with the risk of pregnancy or school dropout.

\section{Pregnancy-related school dropout}

Pregnancy, childbirth, and motherhood transform the context in which adolescents live and make decisions, particularly with regard to household and individual time allocation, including caregiving responsibilities. The resources available within the household-both economic and social-play a role in determining whether or not a young mother resumes her education following childbirth. Likewise, previous school performance, indicated here by age at school entry and prior instances of temporary withdrawal and grade repetition, may indicate a young woman's interest in school, serving as proxy for her motivation and aspirations.

As shown in Table 4, of those who were enrolled in school at the time of pregnancy, 23 percent of 14-19-year-olds and 17 percent of 20-24-year-olds did not drop out of school at the time of their pregnancy. Three percent of 14-19-year-olds and 10 percent of 20-24-year-olds were in grade 12 when they became pregnant and went on to complete that grade. No significant difference is found between the proportion of 14-19-year-olds and the proportion of 20-24-yearolds who dropped out of school at the time of a pregnancy (74 and 72 percent, respectively). The majority of those who reported dropping out because of a pregnancy had not yet returned to school at the time of the survey.

Using logistic regressions, we explore the effect of various individual and household characteristics on the probability that the respondent dropped out of school as the result of becoming pregnant (see Table 5). Model 1 controls for socioeconomic and family background variables. Higher socioeconomic status, measured in quintiles of household-asset ownership, is associated with a decreased risk of dropping out of school, as is urban residence. The education of coresident adults and parental coresidence and survival are not significant, according to this model. Alternative models (results not shown) substituted household age- and sex-composition variables (for example, coresident adult women aged 25-49) for the variables depicting parental coresidence and survival; in no model are these variables found to be statistically significant.

Model 2 adds a set of indicators related the respondent's educational history at the time she became pregnant. The greatest effect is related to school performance: Respondents who had repeated a grade prior to becoming pregnant are almost two times more likely than respondents who had never repeated a grade to drop out of school when they became pregnant. Likewise, those young women who had ever withdrawn temporarily from school are almost two times more likely than those who had not done so to drop out of school after they became pregnant, although this result is not significant in this model. Moreover, those who entered school later are also more likely than others to drop out of school.

Model 3 adds explanatory variables related to the timing of the woman's pregnancy and whether she shares the burden of caring for her child. The grade in which the respondent was enrolled when she became pregnant has a nonlinear impact on her likelihood of dropping out of school. Girls enrolled in grade 8 are the most likely to drop out of school; therefore eighth grade is used as the reference category in the regressions. Those enrolled in grades 4 and 5 are significantly less likely to drop out of school relative to girls enrolled in grade 8 . Although very 
few girls become pregnant at the lowest grade levels, they may have had a greater incentive to remain in school and complete the primary level than those who had just begun studying at the secondary level. Similarly, those enrolled in grade 12 are also significantly less likely to drop out of school when they become pregnant. For those enrolled in grade 7 or grade 12 at the time of becoming pregnant, the perceived returns to finishing the current grade are likely to be higher than at other grades because a major educational qualification is within reach. Controlling for grade at pregnancy, age at pregnancy is not found to be significant. Furthermore, controlling for these pregnancy-related variables, the association between previous school performance and the likelihood of dropout become stronger: both grade repetition and ever having withdrawn temporarily from school are significantly associated with dropout. The odds ratios for these variables are larger than those in Model 2.

Model 3 also includes a variable for whether the respondent was the primary caregiver for her child. Those who were primary caregivers are 78 percent more likely to drop out of school than respondents who were not, even when they shared responsibility with the child's father or another adult.

\section{Return to school following a pregnancy}

Twenty-nine percent of 14-19-year-olds who dropped out of school when they were pregnant had returned to school at the time of the survey, compared with 52 percent of 20-24year-olds. This difference most likely relates to the longer period of time that the older cohort has had to return to school after the pregnancy; younger girls who have dropped out of school because of pregnancy may return to school in the future. In order to deal with the censored nature of this outcome, we use a logistic regression with discrete time data to model the determinants of returning to school as of the date of the survey, with an upper bound of four years or more. (Among older respondents, almost no one returned to school more than four years after dropping out.) Although the analysis is restricted to the 325 women who dropped out of school for pregnancy-related reasons, this approach makes the analysis more robust because these women contribute 591 person-years between dropout and the censored school-return event.

As shown in Table 6, with every year that passes after school dropout, young women are significantly less likely to return to school. Model 1 includes variables controlling for time since dropout and underlying individual and household characteristics. Household wealth, as measured by asset ownership, is not significantly associated with a return to schooling, nor is the level of education of adult household members. Household composition is significantly associated with a return to school, however. Young women living in households where an adult female aged 25 to 49 or aged 60 and older was present are more likely to have returned to school than are young women living in households that lacked an adult woman. The rationale for the age disaggregation presented here is that 25-49-year-olds are normally considered prime-age, economically active adults - in terms of either market or home production, whereas South African women aged 60 and older are eligible for the state old-age pension. Separate regressions (results not shown) that controlled for mother's and father's coresidence and survival instead of household composition show no significant association between these variables and return to school. The presence of older adult women may be a proxy for the childcare and/or financial 
assets available within a household, both of which may facilitate a young woman's return to school.

These results remained statistically significant in Model 2, which added controls for previous school performance. Neither age at school entry nor ever having repeated a grade is significantly associated with the likelihood of returning to school. Young women who had previously withdrawn from school for non-pregnancy-related reasons are half as likely to return to school as are young women who had never withdrawn. This finding may indicate a young woman's motivation and interest in school, independent of her current circumstances.

The final model in Table 6 adds variables related to the timing of the woman's pregnancy and the current childcare arrangement. As with the dropout outcome, grade 8 is the reference category for comparison. For pregnancy-related dropouts that occurred during grades 5 through 9, no significant differences from those that occurred at grade 8 are observed. Those who were enrolled in grades 10,11 , or 12 at the time that they became pregnant and dropped out of school are significantly less likely to have returned by the time of the survey, however; the likelihood of return declines with each higher grade. This finding may reflect the fact that young women who became pregnant in the later grades may not yet have had the chance to return to school. Moreover, when grade at the time of pregnancy is controlled, the variable for prior grade repetition becomes significant. For this outcome, age at pregnancy is nonsignificant. The variable for whether the young mother is the primary caregiver for her child is also nonsignificant. The presence of a coresident female aged 25-49-years-old remains significant, although the presence of an older female is not; this finding may indicate that the resources provided by coresident adult women facilitate a young woman's return to school, independent of caregiving arrangements.

\section{DisCUSSION}

Several important conclusions emerge from our analysis. First, prior school performance is strongly associated with a young woman's likelihood of becoming pregnant while enrolled in school, and, among pregnant schoolgirls, with the likelihood of dropping out of school at the time of pregnancy. Young women with a prior non-pregnancy-related grade repetition are two times more likely to leave school at the time of their pregnancy than are those who had not repeated a grade, and women who had ever withdrawn from school temporarily are two to three times more likely to drop out than those who had not. Among those who dropped out of school for pregnancy-related reasons, those who had ever repeated a grade or who had withdrawn temporarily from school are significantly less likely to return to school following childbirth.

Second, a young woman's access to childcare also plays a significant role in her subsequent educational attainment. Young women who were the primary caregiver for their child are more likely to drop out of school than are women who shared caregiving responsibilities with others. Furthermore, young women who were living with an adult female at the time of the survey are more likely to have returned to school following a pregnancy-related dropout. This variable was not a significant factor in whether women dropped out of school. Because this variable is a measure of current living arrangements, it may represent a situation that was set up so that the young woman could return to school. Being the primary caregiver for her child is not 
a significant factor in the respondent's return to school, perhaps because these young women were able to secure childcare support.

Our research lends some support to the hypothesis that young women who are more invested in their education are less likely to become pregnant while attending school, and, if they do become pregnant, are less likely to drop out of school as a result of the pregnancy. A significant proportion of pregnant schoolgirls in South Africa either remained in school or reenrolled shortly after the birth of their child. Prior poor school performance, measured as grade repetition or temporary withdrawal from school, is highly predictive of which young women will drop out. Research conducted in the United States uses these indicators as measures of disengagement from the educational process, although the present study is the first that we know of to use such variables for a developing country. School engagement is the combination of students' sense of belonging to their school, commitment to school, and commitment to academic work (Smerdon 2002). School behaviors, such as attending class, participating in discussions, completing homework assignments, avoiding distracting behavior, and taking part in extracurricular activities, are used as proxies for engagement and have been shown to be correlated with academic achievement (Manlove 1998; Johnson et al. 2001). Future research concerning schoolgirl pregnancy in developing countries would benefit from expanding questionnaire modules related to girls' previous school experiences.

Students' disengagement from school has also been associated with their perception that few opportunities follow school completion. If young women believe that education offers low returns, they may feel little incentive to avoid early pregnancy. In the United States, Driscoll and her colleagues (2005) found that young women with high educational aspirations are less likely to become pregnant while enrolled in school, even if they live in poor households and neighborhoods with few economic opportunities. Although education is the primary investment strategy used by poor families to escape poverty in less developed countries, evidence from South Africa indicates that labor-market incentives for young black African women aged 15-24 to complete secondary school are not high and may even be declining. This age group has the highest unemployment rate by far (Statistics South Africa 2002); jobless rates for all young people, but especially for this group, rose markedly between 1995 and 2002 (Bhorat 2003). Even young people with completed secondary education have high unemployment rates. In 2002, 34 percent of young unemployed black Africans between 15 and 24 years had grade 12 or tertiary qualifications (Emmett et al. 2004). In addition to employment prospects, education for women holds potential for non-labor-market returns. In conducting focus-group research in South Africa, Kaufman and her colleagues (2001) find that education is strongly associated with valuation of brideprice, which may encourage parents to support their daughters' return to school following early pregnancy and childbirth. Moreover, because job opportunities are so slim for young African women, popular attention has turned recently to the availability of the child-support grant - available to families with children younger than 14 who reside in poor households - as a possible enticement for girls to become pregnant (HSRC 2005). No evidence exists to date to support or refute this hypothesis.

As school participation increases among young women in sub-Saharan Africa, the risk of becoming pregnant while still enrolled in school is likely to increase, given current levels of adolescent childbearing in the region. Although teenage childbearing is not, inherently, a social 
problem, it can interfere with a young woman's educational attainment. Evidence from South Africa suggests that the availability of support in caring for a child and policies that allow a young woman to return to school following childbearing facilitate continued school enrollment. The analysis presented here documents the significant association between prior school experiences and a young woman's educational prospects following childbirth. If indicators of prior school performance are interpreted as proxies for school engagement and motivation, the most effective interventions to encourage continued school participation may be those that seek to counter the disengagement of younger, preadolescent students. As Driscoll and her colleagues (2005) point out, maintaining hope for future educational attainment and the rewards of school achievement can be enough to help poor women from communities with few economic opportunities avoid pregnancy until after they graduate. 


\section{REFERENCES}

Bhorat, H. 2003. "The Post-apartheid Challenge: Labour Demand Trends in the South African Labour Market, 1995-1999.” Development Policy Research Unit Working Paper 03/82. Cape Town: University of Cape Town.

Bledsoe, Caroline. 1992. "The cultural transformation of Western education in Sierra Leone." Africa 62(2): 182-202.

Buchmann, E.J., K. Mensah, and P. Pillay. 2002. "Legal termination of pregnancy among teenagers and older women in Soweto, 1999-2001." South African Medical Journal 92(9): 729-731.

Case, Anne, and Angus Deaton. 1999. "School inputs and education outcomes in South Africa." Quarterly Journal of Economics 114(3): 1,047-1,084.

Connelly, Rachel, Deborah DeGraff, and Deborah Levison. 1996. "Women's employment and child care in Brazil." Economic Development and Cultural Change 44(3): 619-656.

Dickson, Kim Eva, Rachel K. Jewkes, Heather Brown, Jonathan Levin, Helen Rees, and Luyanda Mavuya. 2003. "Abortion service provision in South Africa three years after liberalization of the law." Studies in Family Planning 34(4): 277-284.

Division of Family Health/GTZ Support Unit. 1988. Schoolgirl Pregnancy in Kenya: Report of a Study of Discontinuation Rates and Associated Factors. Nairobi: Ministry of Health, Division of Family Health/GTZ Support Unit.

Driscoll, Anne K., Barbara W. Sugland, Jennifer Manlove, and Angela R. Papillo. 2005. "Community opportunity, perceptions of opportunity, and the odds of an adolescent birth." Youth and Society 37(1): 33-61.

Edmonds, Eric. 2004. "Does Illiquidity Alter Child Labor and Schooling Decisions? Evidence from Household Responses to Anticipated Cash Transfers in South Africa." National Bureau of Economic Research Working Paper No. 10265. Cambridge, MA: National Bureau of Economic Research.

Eloundou-Enyégué, Parfait M. 2004. "Pregnancy-related dropouts and gender inequality in education." Demography 41(3): 509-528.

Emmett, Tony, Linda Richter, Monde Makiwane, Renette du Toit, Heather Brookes, Cheryl Potgieter, Miriam Altman, and Prudence Makhura. 2004. The Status of Youth Report 2003. Pretoria: Human Sciences Research Council. 
Fuller, Bruce and Xiaoyan Liang. 1999. "Which girls stay in school? The influence of family economy, social demands, and ethnicity in South Africa." In Critical Perspectives on Schooling and Fertility in the Developing World. Eds. Caroline H. Bledsoe, John B. Casterline, Jennifer A. Johnson-Kuhn, and John G. Haaga. Washington, DC: National Academy Press.

Hallman, Kelly. 2004. "Socioeconomic Disadvantage and Unsafe Sexual Behaviors Among Young Women and Men in South Africa." Policy Research Division Working Paper No. 190. New York: Population Council.

Hallman, Kelly and Monica Grant. 2003. "Disadvantages and youth schooling, work, and childbearing in South Africa." Paper presented at the Annual Meeting of the Population Association of America, Minneapolis, 1-3 May.

- 2004. "Poverty, pregnancy, and educational attainment of young people in KwaZuluNatal, South Africa." Horizons Research Summary. Washington, DC: Population Council.

Hallman, Kelly, Agnes Quisumbing, Marie T. Ruel, and Bénédicte de la Brière. 2005. "Mothers' work and child care: Findings from the urban slums of Guatemala City." Economic Development and Cultural Change 53(4): 855-886.

Hewett, Paul and Cynthia Lloyd. 2005. "Progress toward education for all: Trends and current challenges for Sub-Saharan Africa," In The Changing Transitions to Adulthood in Developing Countries: Selected Studies. Eds. Cynthia B. Lloyd, Jere R. Behrman, Nelly P. Stromquist, and Barney Cohen. Washington, DC: National Academies Press.

Human Sciences Research Council (HSRC). 2005. Emerging Voices: A Report on Education in South African Rural Communities. Pretoria: HSRC.

Hunter, N. and J. May. 2002. "Poverty, Shocks and School Disruption Episodes among Adolescents in South Africa." CSDS Working Paper No. 35. Durban: University of Natal.

Johnson, Monica Kirkpatrick, Robert Crosnoe, and Glen H. Elder, Jr. 2001. "Students' attachment and academic engagement: The role of race and ethnicity." Sociology of Education 74(4): 318-340.

Johnson-Hanks, J. 2002. “The lesser shame: Adolescent abortion in Cameroon.” Social Science \& Medicine 55(8): 1,337-1,349.

Kaufman, Carol E., Thea de Wet, and Jonathan Stadler. 2001. "Adolescent pregnancy and parenthood in South Africa." Studies in Family Planning 32(2): 147-160. 
Kirby, Douglas. 2001. Emerging Answers: Research Findings on Programs To Reduce Teen Pregnancy. Washington, DC: The National Campaign To Prevent Teen Pregnancy.

Lam, David. 1999. "Generating Extreme Inequality: Schooling, Earnings, and Intergenerational Transmission of Human Capital in South Africa and Brazil." University of Michigan Population Studies Center Research Report 99-439. Ann Arbor: University of Michigan.

- 2000. "Families, communities, and youth outcomes in South Africa." Grant application to National Institutes of Health, National Institute of Child Health and Human Development, United States Public Health Service.

Lloyd, Cynthia and Barbara Mensch. 1999. "Implications of formal schooling for girls' transitions to adulthood in developing countries." In Critical Perspectives on Schooling and Fertility in the Developing World. Eds. Caroline H. Bledsoe, John B. Casterline, Jennifer A. Johnson-Kuhn, and John G. Haaga. Washington, DC: National Academy Press.

Lloyd, Cynthia, Carol Kaufman, and Paul Hewett. 2000. "The spread of primary schooling in sub-Saharan Africa: Implications for fertility change." Population and Development Review 26(3): 483-515.

Magnani, Robert, Kate Macintyre, Ali Mehyrar Karim, Lisanne Brown, Paul Hutchinson, and Anthea Dallimore. 2003. "The impact of life skills education on adolescent sexual risk behaviors." Horizons Research Summary. Washington, DC: Population Council.

Maharaj, Pranitha, Carol Kaufman, and Linda Richter. 2000. "Children's Schooling in South Africa: Transitions and Tensions in Households and Communities." CSDS Working Paper No. 30 . Durban: University of Natal, Centre for Social and Development Studies.

Mahy, M. and N. Gupta. 2002. "Trends and Differentials in Adolescent Reproductive Behavior in sub-Saharan Africa." DHS Analytical Studies No. 3. Calverton, MD: ORC Macro International.

Manlove, Jennifer. 1998. "The influence of high school dropout and school disengagement on the risk of school-age pregnancy." Journal of Research on Adolescence 8(2): 187-220.

Meekers, Dominique and Ghyasuddin Ahmed, 1999. "Pregnancy-related school dropouts in Botswana." Population Studies 53(2): 195-209.

Mensch, Barbara S., Wesley H. Clark, Cynthia B. Lloyd, and Annabel S. Erulkar. 2001. "Premarital sex, schoolgirl pregnancy, and school quality in rural Kenya." Studies in Family Planning 32(4): 285-301. 
Moser, C.O.N. 1996. "Confronting Crisis: A Comparative Study of Household Responses to Poverty and Vulnerability in Four Poor Urban Communities." Environmentally Sustainable Development Studies and Monograph Series No. 8. Washington, DC: World Bank.

National Research Council. 1993. Social Dynamics of Adolescent Fertility in Sub-Saharan Africa. Washington, DC: National Academies Press.

National Research Council and Institute of Medicine of the National Academies (NRC-IOM). 2005. Growing Up Global: The Changing Transitions to Adulthood in Developing Countries. Ed. Cynthia B. Lloyd. Washington, DC: The National Academies Press.

Preston-Whyte, Eleanor. 1990. "Qualitative perspectives on fertility trends among African teenagers.” In South Africa's Demographic Future. Eds. W.P. Mostert and J.M. Lötter. Pretoria: Human Sciences Research Council.

Rutenberg, N., C. Kehus-Alons, L. Brown, K. Macintyre, A. Dallimore, and C. Kaufman. 2001. Transitions to Adulthood in the Context of AIDS in South Africa: Report of Wave I. New York: Population Council.

Shapiro, D. and B.O. Tambashe. 1996. "Family background and early lifecourse transitions in Kinshasa." Journal of Marriage and the Family 58(4): 1,029-1,037.

Singh, Susheela. 1998. "Adolescent childbearing in developing countries: A global review." Studies in Family Planning 29(2): 117-136.

Smerdon, Becky A. 2002. "Students' perceptions of membership in their high schools." Sociology of Education 75(4): 287-305.

South Africa Department of Health (SADOH). 1999. South African Demographic and Health Survey 1998. Pretoria: SADOH.

Statistics South Africa. 2002. Labor Force Survey. Pretoria: Statistics South Africa.

Tanga, T.T. and L.R. Uys. 1996. "The social support system of unmarried pregnant adolescents in the Transkei with particular reference to parents." Curationis 19(1): 50-54.

Turner, A.G., R.J. Magnani, and M. Shuaib. 1996. "A not quite as quick but much cleaner alternative to the expanded programme on immunization (EPI) cluster survey design." International Journal of Epidemiology 25(1):198-203.

United Nations Development Fund for Women (UNDFW). 2000. Progress of the World's Women 2000. UNFEM Biennial Report. New York: United Nations. 
Table 1 Mean values for percentage of women surveyed aged 14-24 who were pregnant at the time they dropped out of school, by reasons they gave for school discontinuation, according to whether they returned to school following the birth of their child, KwaZulu-Natal Province, South Africa

\begin{tabular}{lrcc}
\hline Reason for discontinuation & $\begin{array}{r}\text { Returned to } \\
\text { school }\end{array}$ & $\begin{array}{r}\text { Did not return } \\
\text { to school }\end{array}$ & Total \\
\hline Pregnant & 87.14 & 67.38 & 75.84 \\
Unable to pay school fees & 0.71 & 18.72 & 11.01 \\
Had to care for her child & 9.29 & 2.67 & 5.50 \\
Needed/wanted to work & 0.00 & 3.74 & 2.14 \\
Lacked interest in school & 0.00 & 3.74 & 2.14 \\
Sick & 1.43 & 1.07 & 1.22 \\
Had to care for sick relative & 1.43 & 0.00 & 0.61 \\
Other & 0.00 & 2.67 & 1.53 \\
(N) & $(140)$ & $(187)$ & $(327)$ \\
\hline
\end{tabular}

Figure 1 Schooling outcomes, females aged 14-24, South Africa

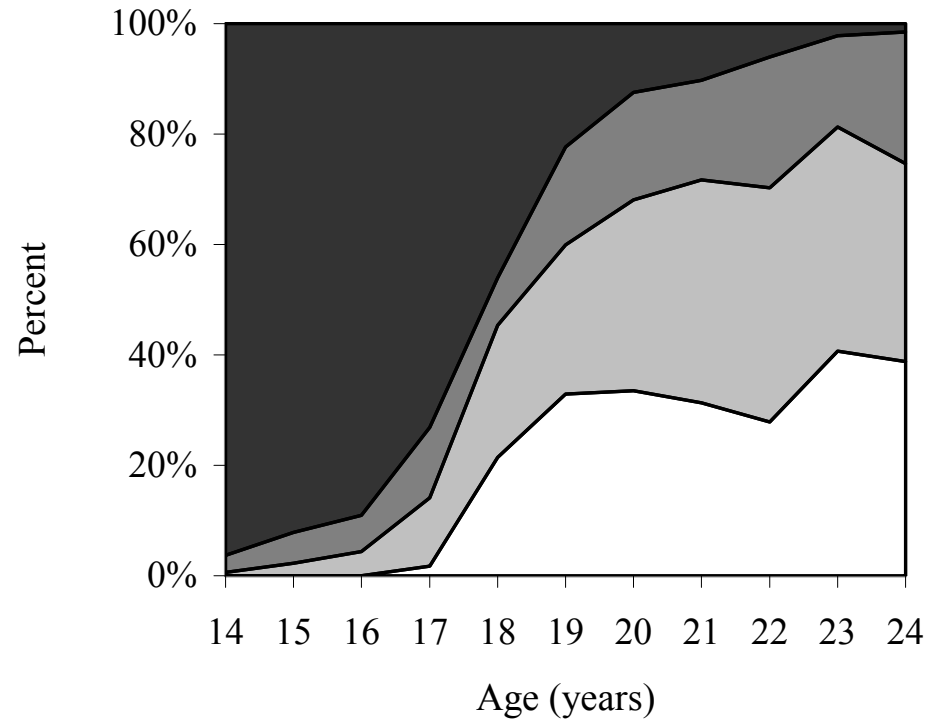

Still enrolled in school and never pregnant

Non-pregnancy-related dropout

$\square$ Schoolgirl pregnancy

Completed grade 12 
Table 2 Percentage distribution of females aged 14-24, by schooling outcomes and by selected independent variables, South Africa

\begin{tabular}{|c|c|}
\hline Variable & Distribution \\
\hline \multicolumn{2}{|l|}{ Schooling outcome } \\
\hline Enrolled in school and never pregnant & 39.1 \\
\hline Non-pregnancy-related dropout & 14.8 \\
\hline Schoolgirl pregnancy & 25.3 \\
\hline Completed grade 12 & 20.9 \\
\hline \multicolumn{2}{|l|}{ Race/ethnicity } \\
\hline African (black) & 76.4 \\
\hline Colored & 1.9 \\
\hline Asian & 17.8 \\
\hline White & 3.8 \\
\hline \multicolumn{2}{|l|}{ Residence } \\
\hline Urban & 79.6 \\
\hline \multicolumn{2}{|l|}{ Household-asset quintile } \\
\hline Low & 22.4 \\
\hline Low-middle & 18.2 \\
\hline Middle & 19.7 \\
\hline High-middle & 23.1 \\
\hline High & 16.7 \\
\hline \multicolumn{2}{|l|}{ Parents' household status } \\
\hline Mother is household member & 65.6 \\
\hline Mother is not household member & 25.9 \\
\hline Mother is dead & 8.6 \\
\hline Father is household member & 38.1 \\
\hline Father is not household member & 38.4 \\
\hline Father is dead & 23.5 \\
\hline \multicolumn{2}{|l|}{ Educational attainment of household head } \\
\hline$<$ Primary & 47.4 \\
\hline Primary and some secondary & 33.6 \\
\hline Secondary, not matriculated & 8.0 \\
\hline Secondary, matriculated & 8.3 \\
\hline Higher & 2.8 \\
\hline Age at school entry (mean years) & 6.4 \\
\hline Ever withdrew from school temporarily & 11.5 \\
\hline Ever repeated a grade & 21.3 \\
\hline$(\mathrm{N})$ & $(2,164)$ \\
\hline
\end{tabular}


Table 3 Multinomial logit regression based on discrete time data, for relative-risk ratios for school dropout and schoolgirl pregnancy relative to continued school enrollment for females aged 14-24, South Africa

\begin{tabular}{|c|c|c|c|c|}
\hline \multirow[b]{2}{*}{ Variable } & \multicolumn{2}{|c|}{ Model 1} & \multicolumn{2}{|c|}{ Model 2} \\
\hline & $\begin{array}{c}\begin{array}{c}\text { Dropout } \\
\text { (versus }\end{array} \\
\text { still enrolled) }\end{array}$ & $\begin{array}{c}\text { Schoolgirl } \\
\text { pregnancy (versus } \\
\text { still enrolled) }\end{array}$ & $\begin{array}{c}\begin{array}{c}\text { Dropout } \\
\text { (versus }\end{array} \\
\text { still enrolled) }\end{array}$ & $\begin{array}{c}\text { Schoolgirl } \\
\text { pregnancy (versus } \\
\text { still enrolled) }\end{array}$ \\
\hline \multicolumn{5}{|l|}{ School grade } \\
\hline Grade $8(\mathrm{r})$ & 1.00 & 1.00 & 1.00 & 1.00 \\
\hline Grades $1-4$ & $0.18 * * *$ & $0.01 * * *$ & $0.16 * * *$ & $0.01 * * *$ \\
\hline Grade 5 & $0.39 * *$ & $0.08 * * *$ & $0.34 * *$ & $0.07 * * *$ \\
\hline Grade 6 & $0.46^{*}$ & $0.20 * * *$ & $0.42 * *$ & $0.18 * * *$ \\
\hline Grade 7 & 1.15 & 0.71 & 1.10 & 0.69 \\
\hline Grade 9 & $2.41 * * *$ & $1.88 * * *$ & $2.48 * * *$ & $1.96 * * *$ \\
\hline Grade 10 & $2.98 * * *$ & $3.64 * * *$ & $3.20 * * *$ & $4.04 * * *$ \\
\hline Grade 11 & $13.19 * * *$ & $5.99 * * *$ & $14.55 * * *$ & $7.53 * * *$ \\
\hline Grade 12 & 0.59 & $10.40 * * *$ & 0.71 & $15.59 * * *$ \\
\hline \multicolumn{5}{|l|}{ Race/ethnicity } \\
\hline Black (r) & 1.00 & 1.00 & 1.00 & 1.00 \\
\hline Colored & 0.41 & 0.58 & 0.54 & 0.81 \\
\hline Asian & 1.33 & $0.09 * * *$ & $1.71 *$ & $0.18 * * *$ \\
\hline White & 1.12 & 0.27 & 1.33 & 0.46 \\
\hline \multicolumn{5}{|c|}{ Socioeconomic status } \\
\hline Low (r) & 1.00 & 1.00 & 1.00 & 1.00 \\
\hline Low-middle & $0.46 * * *$ & $0.63 * * *$ & $0.48 * * *$ & 0.78 \\
\hline Middle & $0.21 * * *$ & $0.61 * * *$ & $0.24 * * *$ & 0.81 \\
\hline High-middle & $0.26 * * *$ & $0.49 * * *$ & $0.31 * * *$ & $0.70 *$ \\
\hline High & $0.10 * * *$ & $0.30 * * *$ & $0.11 * * *$ & $0.40 * * *$ \\
\hline \multicolumn{5}{|c|}{ Parents' household status } \\
\hline \multicolumn{5}{|c|}{ Mother is household member } \\
\hline Yes (r) & 1.00 & 1.00 & 1.00 & 1.00 \\
\hline No & $1.59 * *$ & 0.97 & $1.53 * *$ & 1.01 \\
\hline \multicolumn{5}{|c|}{ Mother is dead } \\
\hline Yes (r) & 1.00 & 1.00 & 1.00 & 1.00 \\
\hline No & $1.66^{*}$ & 1.28 & $1.64 *$ & 1.37 \\
\hline \multicolumn{5}{|c|}{ Father is household member } \\
\hline Yes (r) & 1.00 & 1.00 & 1.00 & 1.00 \\
\hline No & 1.17 & $1.38^{*}$ & 1.18 & $1.38^{*}$ \\
\hline \multicolumn{5}{|l|}{ Father is dead } \\
\hline Yes (r) & 1.00 & 1.00 & 1.00 & 1.00 \\
\hline No & 1.08 & $1.51 * *$ & 1.06 & $1.69 * * *$ \\
\hline Household size & 1.03 & $1.05^{* *}$ & 1.02 & $1.04 *$ \\
\hline
\end{tabular}


Table 3 (continued)

\begin{tabular}{|c|c|c|c|c|}
\hline \multicolumn{5}{|l|}{$\begin{array}{l}\text { Educational attainment of } \\
\text { household head }\end{array}$} \\
\hline$<$ Primary $(\mathrm{r})$ & 1.00 & 1.00 & 1.00 & 1.00 \\
\hline Primary and some secondary & $0.59 * * *$ & $0.72 * *$ & $0.62 * *$ & $0.74 *$ \\
\hline Secondary, not matriculated & $0.43 * *$ & $0.41 * * *$ & $0.48^{*}$ & $0.58 *$ \\
\hline Secondary, matriculated & $0.30 * *$ & $0.30 * * *$ & $0.34 * *$ & $0.32 * * *$ \\
\hline Higher & $0.12 *$ & $0.21 * *$ & 0.15 & 0.43 \\
\hline \multicolumn{5}{|l|}{ Residence } \\
\hline Rural (r) & 1.00 & 1.00 & 1.00 & 1.00 \\
\hline Urban & 0.92 & 0.94 & 1.12 & 1.22 \\
\hline Age at school entry (mean years) & & & $1.48^{* * *}$ & $1.65^{* * *}$ \\
\hline \multicolumn{5}{|l|}{$\begin{array}{l}\text { Ever temporarily withdrew } \\
\text { from school }\end{array}$} \\
\hline No $(r)$ & & & 1.00 & 1.00 \\
\hline Yes & & & $2.24 * *$ & 1.03 \\
\hline \multicolumn{5}{|l|}{ Ever repeated a grade } \\
\hline No (r) & & & 1.00 & 1.00 \\
\hline Yes & & & $1.64 * *$ & $7.23 * * *$ \\
\hline Number of exposure-grades & 17,582 & & 17,582 & \\
\hline $\operatorname{LR} \chi^{2}$ & 1778.94 & & 2248.8 & \\
\hline Probability $>\chi^{2}$ & 0.0 & & 0.0 & \\
\hline Pseudo $\mathrm{R}^{2}$ & 0.2546 & & 0.3218 & \\
\hline
\end{tabular}

*Significant at $\mathrm{p}<0.05 ; * * \mathrm{p}<0.01 ; * * * \mathrm{p}<0.001 . \quad(\mathrm{r})=$ Reference category. 
Table 4 Percentage of females aged 14-24, by school attendance at the time they became pregnant, according to age group, South Africa

\begin{tabular}{lrr}
\hline & \multicolumn{2}{c}{ Age group } \\
\cline { 2 - 3 } School attendance & $\mathbf{1 4 - 1 9}$ & $\mathbf{2 0 - 2 4}$ \\
\hline Did not drop out the year of the pregnancy & 23.0 & 17.4 \\
Completed grade 12 the year of the pregnancy & 3.2 & 10.4 \\
Dropped out of school the year of the pregnancy & 73.8 & 72.2 \\
Returned to school following pregnancy-related dropout & 29.0 & 51.8 \\
(N) & $(187)$ & $(270)$ \\
\hline
\end{tabular}


Table 5 Odds ratios from logistic regression of the likelihood that females aged 14-24 who became pregnant while enrolled in school will drop out, by selected variables, South Africa

\begin{tabular}{|c|c|c|c|}
\hline Variable & Model 1 & Model 2 & Model 3 \\
\hline \multicolumn{4}{|l|}{ Race } \\
\hline African (black) (r) & 1.00 & 1.00 & 1.00 \\
\hline Colored & 0.70 & 0.76 & 1.34 \\
\hline Asian & 0.88 & 1.55 & 3.81 \\
\hline White $^{\mathrm{a}}$ & - & - & - \\
\hline \multicolumn{4}{|l|}{ Socioeconomic status } \\
\hline Low (r) & 1.00 & 1.00 & 1.00 \\
\hline Low-middle & 0.67 & 0.70 & 0.72 \\
\hline Middle & $0.35 * * *$ & $0.39 * *$ & $0.40 *$ \\
\hline High-middle & $0.32 * * *$ & $0.35^{* *}$ & $0.37 *$ \\
\hline High & $0.28 *$ & $0.27 *$ & $0.26 *$ \\
\hline \multicolumn{4}{|l|}{ Parents' household status } \\
\hline \multicolumn{4}{|l|}{ Mother is household member } \\
\hline Yes (r) & 1.00 & 1.00 & 1.00 \\
\hline No & 1.37 & 1.33 & 1.59 \\
\hline \multicolumn{4}{|l|}{ Mother is dead } \\
\hline Yes (r) & 1.00 & 1.00 & 1.00 \\
\hline No & 2.20 & $2.35^{*}$ & 2.18 \\
\hline \multicolumn{4}{|l|}{ Father is household member } \\
\hline Yes (r) & 1.00 & 1.00 & 1.00 \\
\hline No & 0.99 & 0.97 & 0.71 \\
\hline \multicolumn{4}{|l|}{ Father is dead } \\
\hline Yes (r) & 1.00 & 1.00 & 1.00 \\
\hline No & 1.28 & 1.39 & 1.09 \\
\hline Household size & $1.08^{*}$ & $1.09 *$ & $1.11^{*}$ \\
\hline \multicolumn{4}{|c|}{ Educational attainment of household head } \\
\hline$<$ Primary (r) & 1.00 & 1.00 & 1.00 \\
\hline Primary and some secondary & 1.03 & 1.17 & 1.42 \\
\hline Secondary, not matriculated & 1.26 & 1.93 & 2.45 \\
\hline Secondary, matriculated & 0.37 & 0.59 & 0.87 \\
\hline Higher & 0.39 & 0.75 & 0.87 \\
\hline \multicolumn{4}{|l|}{ Residence } \\
\hline Rural (r) & 1.00 & 1.00 & 1.00 \\
\hline Urban & $0.52 *$ & 0.61 & 0.62 \\
\hline Age at school entry (years) & & $1.22 *$ & 1.28 \\
\hline \multicolumn{4}{|c|}{ Ever withdrew from school temporarily } \\
\hline No $(r)$ & & 1.00 & 1.00 \\
\hline Yes & & 1.84 & $2.70 *$ \\
\hline \multicolumn{4}{|l|}{ Ever repeated a grade } \\
\hline No $(r)$ & & 1.00 & 1.00 \\
\hline Yes & & $1.74 * * *$ & $2.00 * * *$ \\
\hline
\end{tabular}


Table 5 (continued)

Pregnancy occurred in

Grade 8 (r)

Grade 4

1.00

Grade 5

Grade 6

Grade 7

Grade 9

Grade 10

Grade 11

Grade 12

$0.04 *$

$0.09 *$

0.63

0.74

0.56

0.59

0.53

0.17 *

Age at pregnancy (years)

0.81

Primary caregiver for her child

No (r)

1.00

Yes

$1.78 *$

Number of observations

LR $\chi^{2}(16)$

Probability $>\chi^{2}$

Pseudo $\mathrm{R}^{2}$

443

38.39

443

443

Log-likelihood ratio

0.0013

0.0739

59.51

106.4

$-240.5611$

0.1145

0.0

*Significant at $\mathrm{p}<0.05 ; *{ }^{*} \mathrm{p}<0.01 ; * * * \mathrm{p}<0.001$.

$(\mathrm{r})=$ Reference category.

$-230.0003$

0.2048

$-206.5528$

${ }^{a}$ Dropped out 
Table 6 Odds ratios from logistic regression using discrete time data of the likelihood that females aged 14-24 will return to school after a pregnancy-related dropout, South Africa

\begin{tabular}{|c|c|c|c|}
\hline Variable & Model 1 & Model 2 & Model 3 \\
\hline \multicolumn{4}{|l|}{ Time since dropout } \\
\hline One year (r) & 1.00 & 1.00 & 1.00 \\
\hline Two years & $0.42 * * *$ & $0.44 * * *$ & $0.45^{* *}$ \\
\hline Three years & $0.32 * * *$ & $0.32 * * *$ & $0.34 * *$ \\
\hline Four years + & $0.19 * *$ & $0.20 * *$ & $0.24 * *$ \\
\hline \multicolumn{4}{|l|}{ Socioeconomic status } \\
\hline Low (r) & 1.00 & 1.00 & 1.00 \\
\hline Low-middle & 1.05 & 1.08 & 1.21 \\
\hline Middle & 1.08 & 1.01 & 1.25 \\
\hline High-middle & 1.16 & 1.23 & 1.31 \\
\hline High & 1.74 & 1.73 & 1.77 \\
\hline \multicolumn{4}{|c|}{ Educational attainment of household head } \\
\hline$<$ Primary $(\mathrm{r})$ & 1.00 & 1.00 & 1.00 \\
\hline Primary and some secondary & 0.98 & 0.90 & 0.98 \\
\hline Secondary, not matriculated & 0.49 & 0.38 & 0.69 \\
\hline Secondary, matriculated & 1.78 & 1.47 & 1.50 \\
\hline \multicolumn{4}{|l|}{ Adult in household } \\
\hline None (r) & 1.00 & 1.00 & 1.00 \\
\hline Female aged $25-49$ & $1.48 * *$ & $1.50 * *$ & $1.60 * *$ \\
\hline Female aged $50-59$ & 1.70 & 1.69 & $1.99^{*}$ \\
\hline Female aged 60 or older & $1.89 *$ & $1.74 *$ & 1.59 \\
\hline Household size & 0.93 & 0.93 & 0.94 \\
\hline \multicolumn{4}{|l|}{ Residence } \\
\hline Rural (r) & 1.00 & 1.00 & 1.00 \\
\hline Urban & 0.82 & 0.80 & 0.89 \\
\hline Age at school entry (years) & & 1.01 & 0.79 \\
\hline \multicolumn{4}{|l|}{ Ever repeated a grade } \\
\hline No (r) & & 1.00 & 1.00 \\
\hline Yes & & 0.96 & $0.72 *$ \\
\hline \multicolumn{4}{|c|}{ Ever withdrew from school temporarily } \\
\hline No (r) & & 1.00 & 1.00 \\
\hline Yes & & $0.45^{*}$ & $0.47^{*}$ \\
\hline \multicolumn{4}{|l|}{ Pregnancy occurred in } \\
\hline Grade 8 (r) & & & 1.00 \\
\hline Grade 5 & & & 1.06 \\
\hline Grade 6 & & & 1.02 \\
\hline Grade 7 & & & 0.48 \\
\hline Grade 9 & & & 0.51 \\
\hline Grade 10 & & & $0.34 * *$ \\
\hline Grade 11 & & & $0.19 * * *$ \\
\hline Grade 12 & & & $0.01 * * *$ \\
\hline
\end{tabular}


Table 6 (continued)

Age at pregnancy (years)

Primary caregiver for her child

No (r)

Yes

1.00

0.82

Number of person-years

$\operatorname{LR} \chi^{2}(15)$

Probability $>\chi^{2}$

Pseudo $\mathrm{R}^{2}$

Log-likelihood ratio

$\begin{array}{ccc}591 & 591 & 589 \\ 49.22 & 56.56 & 94.27 \\ 0.0 & 0.0 & 0.0 \\ 0.0763 & 0.0877 & 0.1465 \\ -297.765 & -294.099 & -274.703\end{array}$

*Significant at $\mathrm{p}<0.05 ; * * \mathrm{p}<0.01 ; * * * \mathrm{p}<0.001 . \quad(\mathrm{r})=$ Reference category. 


\section{POLICY RESEARCH DIVISION WORKING PAPERS}

If still in print, single copies of up to three working papers from 1989 through 2003 are available free of charge.

Beginning with the 2004 issues, working papers are no longer available in print format. Instead they are distributed electronically. As each new paper is completed subscribers are notified by e-mail and a link to the paper is provided.

To subscribe to the Policy Research Division working paper e-mail notification list, or to obtain back issues from 1989 to 2003, please send your request to prdwp@popcouncil.org.

PDFs of recent issues are available at www.popcouncil.org/publications/wp/prd/rdwplist.html

2006

212 Monica Grant and Kelly Hallman, "Pregnancy-related school dropout and prior school performance in South Africa."

211 Kelly Hallman, Sara Peracca, Jennifer Catino, and Marta Julia Ruiz, "Multiple disadvantages of Mayan females: The effect of gender, ethnicity, poverty, and residence on education in Guatemala."

210 Geoffrey McNicoll, "Policy lessons of the East Asian demographic transition."

209 Cynthia B. Lloyd, Cem Mete, and Monica J. Grant, "The implications of changing educational and family circumstances for children's grade progression in rural Pakistan: 1997-2004.”
2005

208 James F. Phillips, Ayaga A. Bawah, and Fred N. Binka, "Accelerating reproductive and child health program development: The Navrongo Initiative in Ghana."

207 John Bongaarts and Griffith Feeney, "The quantum and tempo of life-cycle events."

206 Barbara S. Mensch, Monica J. Grant, and Ann K. Blanc, "The changing context of sexual initiation in sub-Saharan Africa."

205 Geoffrey McNicoll, "Population and sustainability."

204 John Bongaarts, "The causes of stalling fertility transitions."

203 Ayaga A. Bawah and Fred N. Binka, "How many years of life could be saved if malaria were eliminated from a hyperendemic area of northern Ghana?" 

marriage among men and women in the developing world."

201 Zachary Zimmer, "Active life expectancy and functional limitations among older Cambodians: Results from a 2004 survey."

200 Brian Wells Pence, Philomena Nyarko, James F. Phillips, and Cornelius Debpuur, "The effect of community nurses and health volunteers on child mortality: The Navrongo Community Health and Family Planning Project."

199 Zachary Zimmer, Linda G. Martin, Mary Beth Ofstedal, and Yi-Li Chuang, "Education of adult children and mortality of their elderly parents in Taiwan."

198 Mian Bazle Hossain, James F. Phillips, and Thomas K. LeGrand, "The impact of childhood mortality on fertility in six rural thanas of Bangladesh."

197 Kristine R. Baker, Mary Beth Ofstedal, Zachary Zimmer, Zhe Tang, and Yi-Li Chuang, "Reciprocal effects of health and economic well-being among older adults in Taiwan and Beijing."

196 Mark R. Montgomery and Paul C. Hewett, "Poverty and children's schooling in urban and rural Senegal."

2004

195 Luciana Suran, Sajeda Amin, Lopita Huq, and Kobita Chowdury, "Does dowry improve life for brides? A test of the bequest theory of dowry in rural Bangadesh."

194 Barbara S. Mensch, Monica J. Grant, Mary P. Sebastian, Paul C. Hewett, and Dale Huntington. "The effect of a livelihoods intervention in an urban slum in India: Do vocational counseling and training alter the attitudes and behavior of adolescent girls?"

193 Amanda Ritchie, Cynthia B. Lloyd, and Monica Grant. "Gender differences in time use among adolescents in developing countries: Implications of rising school enrollment rates."

192 John Bongaarts. "Long-range trends in adult mortality: Models and projection methods."

191 John Koku Awoonor-Williams, Ellie S. Feinglass, Rachel Tobey, Maya N. Vaughan-Smith, Frank K. Nyonator, Tanya C. Jones, and James F. Phillips, "Bridging the gap between evidence-based innovation and national healthsector reform in Ghana."

190 Kelly Hallman, "Socioeconomic disadvantage and unsafe sexual behaviors among young women and men in South Africa."

189 Toshiko Kaneda, Zachary Zimmer, and Zhe Tang, "Differentials in life expectancy and active life expectancy by socioeconomic status among older adults in Beijing." 
188 Cynthia B. Lloyd and Monica J.

Grant, "Growing up in Pakistan:

The separate experiences of males and females."

187 Zachary Zimmer, Xianghua Fang, Toshiko Kaneda, Zhe Tang, and Julia Kwong. "Trends and transitions in children's coresidence with older adults in Beijing municipality."

186 Sajeda Amin and Alaka M. Basu. "Popular perceptions of emerging influences on mortality and longevity in Bangladesh and West Bengal."

185 John Bongaarts. "Population aging and the rising cost of public pensions."

184 Mark R. Montgomery and Paul C. Hewett. "Urban poverty and health in developing countries: Household and neighborhood effects." 